\title{
RECENSÃO AAVV, CHARTA DER GRUNDRECHTE DER EUROPÄISCHEN UNION, JÜRGEN MEYER (ED.), 4. ㄹ EDIÇÃO, BADEN-BADEN, VIENA E BASEL, NOMOS, FACULTAS. WUV E HELBING LICHTENHAHN, 2014
}

\begin{abstract}
Artur Flamínio da Silva Licenciado em Direito pela Faculdade de Direito da Universidade de Lisboa. Mestre e Doutorando em Direito Público pela Faculdade de Direito da Universidade Nova de Lisboa.
\end{abstract}

Submissão em 04.05.2015. Aprovação em 21.09.2015

A 1 de Dezembro de 2009, a entrada em vigor do Tratado de Lisboa teve, entre outras, a virtualidade de atribuir força vinculativa à Carta dos Direitos Fundamentais da União Europeia (doravante Carta). Com efeito, nos termos do artigo 6. $\mathrm{o}$ do Tratado da União Europeia “[a] União reconhece os direitos, as liberdades e os princípios enunciados na Carta dos Direitos Fundamentais da União Europeia [...] que tem o mesmo valor jurídico que os Tratados". Neste contexto, deve mencionar-se que este facto é considerado um importante passo no sentido de atingir uma constitucionalização do Direito da União Europeia ${ }^{53}$. Por outro, a Carta também tem ganho protagonismo com a recente decisão Åkerberg Fransson, na qual o Tribunal de Justiça entendeu que «quando uma regulamentação nacional se enqua-

\footnotetext{
${ }^{53}$ Este objectivo que já se encontrava patente no processo de elaboração da Carta, uma vez que se tratava de «avanço constitucional» do Direito da União Europeia. Cfr. Miguel Poiares Maduro, A Constituição Plural - Constitucionalismo e União Europeia, Principia, Cascais, 2006, p. 301. Sobre a génese deste instrumento jurídico, cfr., entre tantos outros, com indicações, David Anderson e Cian C. Murphy, The Charter of Fundamental Rights, in EU Law After Lisbon, Andrea Biondi, Piet Eeckhout e Stefanie Ripley (Ed.), Oxford, Oxford University Press, 2012, pp. 155 e ss.
} 
dra no âmbito de aplicação» do Direito da União Europeia, consequentemente “[a] aplicabilidade do direito da União implica a aplicabilidade dos direitos fundamentais garantidos pela Carta" ${ }^{24}$. No entanto, também é relevante recordar as dificuldades que envolvem a integração formal da Convenção Europeia dos Direitos do Homem nas regras jurídicas da União Europeia, num processo que, na sequência do parecer n. $2 / 2013$, de 18 de Dezembro de 2014, do Tribunal de Justiça parece ter, por ora, vetado ao insucesso ${ }^{55}$. De qualquer modo, entre outros, estes factos têm demonstrado que o estudo da Carta é imprescindível e actual.

Neste contexto, é de realçar que obras como aquela que recenseamos são indispensáveis para compreender os problemas jurídicos de um instrumento jurídico cada vez mais relevante na temática dos Direitos Humanos. É, assim, de constatar que o mérito do Editor Jürgen Meyer é inegável. A obra recenseada é um marco fundamental no estudo da Carta, contando com o contributo de seis autores (Norbert Bernsdorf, Martin Borowski, Albin Eser, Sven Hölscheidt, Siegfried Magiera e Beate Rudolf) e com anotações do próprio Professor Doutor Jürgen Meyer ${ }^{56}$.

Em particular, devemos denunciar que a relevância desta monografia se revela na forma simples, mas extraordinariamente rigorosa em que expõe a realidade jurídica da Carta que se manifesta na recolha bibliográfica (que não se cinge exclusivamente à bibliografia alemã, mas que conta com elementos bibliográficos de língua inglesa, espanhola, francesa ou mesmo italiana) e na argumentação desenvolvida pelos autores.

Este facto permite, assim, tratar-se de uma obra que é um marco no estudo dos problemas jurídicos da Carta: quer seja num âmbito de uma investigação pós-graduada, de graduação ou de uma mera actividade principal enquanto advogado ou académico. Este texto é inescapável para todos aqueles que querem compreender a envolvência jurídica dos direitos fundamentais consagrados pela Carta.

\footnotetext{
${ }^{540}$ Ponto 19 e e 21 do Acórdão de 23 de Fevereiro de 2013 do Tribunal de Justiça, processo n. ${ }^{\circ}$ C-617/10. Para uma apreciação crítica desta jurisprudência, com amplas indicações, cfr. EIKE MichaEL Frenzel, «Die Charta der Grundrechte als Massstab für mitgliedstaatliches Handeln zwischen EffekTiVIERUNG Und Hyperintegration», IN DER STAAT, VOL. 53, N. ${ }^{\circ} 1$ (2014), PP. 1 e SS.

${ }^{550}$ Para uma apreciação crítica deste parecer, cfr., por exemplo, Christoph Krenn, Autonomy and Effectiveness as Common Concerns: A Path to ECHR Accession After Opinion 2/13, in German Law Journal, n. ${ }^{\circ} 16$ (2015), disponível em <http://www.germanlawjournal.com/index.php?pageID=11\&artID=1669>. Sobre as consequências da integração da Convenção Europeia dos Direitos do Homem no Direito da União Europeia, cfr. Walther Michl, DIE ÜBERPRÜFUNG DES UNIONSRECHTS AM MASSSTAB DER EMRK, Tubinga, Mohr Siebeck, 2014, pp. 146 e ss. e Julie Vondung, Die ARChiteKtur DES EUROPäISCHeN GRUNDRECHTSSCHUtZeS NACH DEM BeITRITT DER EU zUR EMRK, Tubinga, MoHr SiebeCK, 2012, PP. 123 E SS.

${ }^{560}$ Não é, no entanto, a única obra colectiva de anotação à Carta. Cfr., por exemplo, em língua portuguesa, a obra colectiva coordenada por Alessandra Silveira e Mariana Canotilho, CARTa DOS DiREITos Fundamentais da União Europeia, Coimbra, Almedina, 2013 E, em inglês, AAVV, The Charter of Fundamental Rights. A Commentary, Steve Peters, Tamara Hervey, Jeff Kenner e Angela Ward (ED.), OXFORD, HART, 2014.
}

Revista DIREITO UFMS | Campo Grande, MS | v. 2 | n. 1 | p. 183 - 187 | jul./dez. 2016 
Por outro lado, refira-se que, em termos de organização da exposição do texto, nos parece de extrema utilidade a opção por uma nota introdutória a anteceder cada anotação de um artigo individualmente considerado, uma vez que permite ao leitor efectuar um estudo integrado do texto. Neste sentido, a extensão global de 859 páginas permite um apurado desenvolvimento dos artigos comentados pelos autores. Em especial, deve, no entanto, ser referenciada o estudo desenvolvido do preâmbulo da Carta num total de 50 páginas (sem paralelo noutros estudos), uma vez que se trata de um importante instrumento de interpretação da Carta.

Um dos pontos fortes do comentário reside, por outro lado, na aposta por uma explicação que apresenta sucintamente o contexto histórico de cada artigo da Carta e o valor interpretativo que daí deriva. Este facto permite ao leitor ganhar um conhecimento aprofundado prático do contexto em que surgiu cada disposição da Carta.

Em suma, podemos afirmar, com toda a certeza, que se trata de uma obra indispensável na temática dos direitos fundamentais que emergem do Direito da União Europeia. 